\title{
Species size affects hatching response to different temperature regimes in a rotifer cryptic species complex
}

\author{
Aleksandra Walczyńska • Manuel Serra
}

Received: 6 June 2013/Accepted: 25 June 2013/Published online: 5 July 2013

(C) The Author(s) 2013. This article is published with open access at Springerlink.com

\begin{abstract}
The strategy of decreasing size with increasing temperature known as Bergmann's rule operates at geographic scale and in spite of extensive studies still presents a puzzle to researches. The aim of this work was to verify whether patterns of diapausing egg hatching of closely related species are consistent with the expectations from Bergmann's rule. In a laboratory study of the cryptic species complex of the rotifer Brachionus plicatilis, the response to temperature $\left(17.5,22.5\right.$, and $\left.25.0^{\circ} \mathrm{C}\right)$ of diapausing eggs collected in a pond where the three tested species coexist was assessed by (1) the number of hatchlings emerging or (2) the time needed to hatch. Our results show that the response to temperature from the sediment egg bank is species-dependent. In line with Bergmann's rule, an association was observed between the hatching response to temperature and organism size. The biggest species increased its proportion in the hatchlings as temperature decreased, and vice versa. The intermediate size species showed an intermediate pattern. Nevertheless, temperature showed a general positive effect on hatching success. Time needed to hatch suggests a signature of Bergmann's rule, but other factors seem to be affecting this parameter. This is the first study to demonstrate differences in the thermal dependence of diapausing egg hatching among closely related species with different body sizes, and it supports that Bergmann's rule can be applied to diapause, an important phase in many invertebrate lifecycles.
\end{abstract}

Keywords Adaptation - Bergmann's rule · Body size - Cryptic species · Egg bank · Resting eggs

A. Walczyńska $(\bowtie)$

Institute of Environmental Sciences, Jagiellonian University, Gronostajowa 7, 30-387 Kraków, Poland e-mail: aleksandra.walczynska@uj.edu.pl

M. Serra

Institute Cavanilles for Biodiversity and Evolutionary Biology, University of Valencia, A.O. 2085, 46071 Valencia, Spain 


\section{Introduction}

Related taxa usually vary in adult size. This variation can be driven by a number of internal and external factors, one of which is temperature. Bergmann (1847, cited in Watt et al. 2010) was the first to observe temperature-related differences in the body size of related species, though initially his rule applied only to vertebrates at different latitudes. The socalled 'extended Bergmann's rule' describes genetic differences between closely related species of all living organisms, leading to slower growth and larger size at high latitudes (i.e., low mean temperature) than closer to the equator. The adaptive role of this universal phenomenon has not been unequivocally established, and the rationale for such an adaptation is poorly understood (Angilletta 2008).

Closely related species coexisting in the same environment could be used to shed new light on the adaptive significance of body size (Angilletta and Dunham 2003), as they have similar morphology and ecology. The cryptic species complex Brachionus plicatilis rotifer offers such a model. A cryptic species complex is a set of biological species not distinguished earlier due to their morphological similarity. Previously thought to be a single cosmopolitan eurioic species (Walker 1981), the B. plicatilis complex apparently contains at least 14 species (Suatoni 2003). Three of them co-occur in small ponds on the Mediterranean coast of Spain (Gómez et al. 1995; Ortells et al. 2003). In order from largest to smallest, they are B. plicatilis (Müller) sensu stricto, B. ibericus and B. rotundiformis (Tschugunoff) (Gómez et al. 1995; Ciros-Pérez et al. 2001a; Lapesa et al. 2004; Fig. 1). Their morphology (Gómez et al. 1995; Ciros-Pérez et al. 2001a), reproduction (Carmona et al. 1995; Gómez et al. 1997) and ecological specialization (Gómez et al. 1995, 1997; Ciros-Pérez et al. 2001b; Lapesa et al. 2002; Montero-Pau et al. 2011; Montero-Pau and Serra 2011) have been described in detail. Brachionus is a group of cyclically parthenogenetic rotifers which are seasonally active in the water column of lakes and ponds. These organisms sexually produce diapausing eggs that remain in the sediment and can survive adverse conditions. When good conditions resume, a fraction of these eggs hatches, producing clones via parthenogenetic proliferation. Partial hatching is regarded as a bethedging strategy, the by-product being huge banks of diapausing eggs (García-Roger 2006a), similar to seed banks, where the eggs can remain viable for decades. B. plicatilis, $B$. ibericus and $B$. rotundiformis are involved in seasonal succession with partially overlapping temporal distributions. B. plicatilis tends to occur in the water column in winter, $B$. ibericus is present in spring and B. rotundiformis in spring and summer (Gómez et al. 1995). Being filtering feeders that consume microalgae, they compete. Laboratory studies have shown that competition can result in exclusion or coexistence, depending on conditions (Ciros-Pérez et al. 2001b).

Production of diapausing eggs, essential for survival of the genotype during adverse periods, is regarded as an interannual fitness measure (Serra and King 2001). The expenditure of resources on diapausing egg production is huge: egg bank size is estimated at billions of eggs even in a small pond (García-Roger 2006a). An important fitness component of the rotifer life cycle is related to diapausing egg hatching. Hatching at the wrong time means a smaller chance to compete and proliferate. For instance, during the increase of lake temperature from winter to summer, early hatching would incur the risk of exposure to lethally low temperature, and late hatching would mean wasting proliferation time in a competitive scenario. Hence, the theoretical expectation is that the hatching response to temperature is correlated with the optimal temperature for a given species, the eggs being programmed to hatch at the optimal temperature for the adults. Therefore, from Bergmann's rule, the expectation is a hatching response to temperature dependent upon 


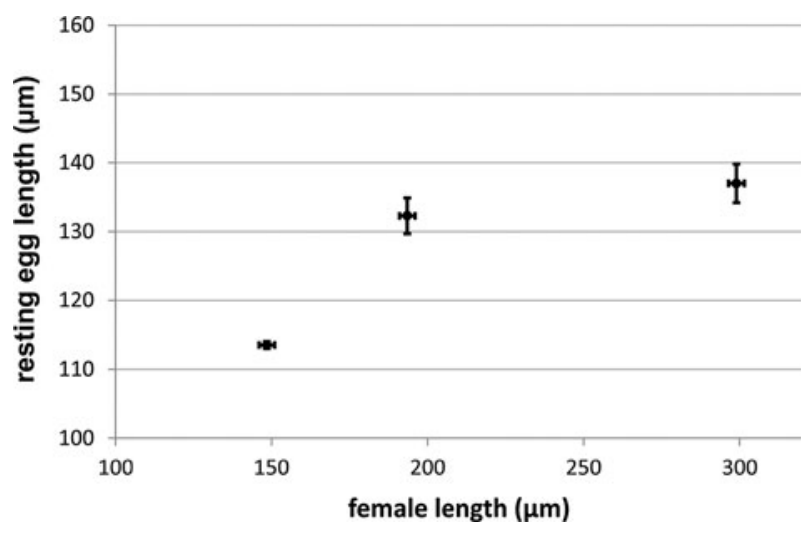

Fig. 1 Mean resting egg size related to mean female size for three species of the B. plicatilis cryptic species complex (mean \pm SE; data from Ciros-Pérez et al. 2001a)

species body size, with a tendency for large body size animals to have high egg hatching rates at low temperature. Additionally, it is also arguable that, if large size has a relative physiological advantage at low temperature, it might affect the egg developmental performance, with large eggs being more efficiently developed at low temperature if compared to small eggs. Adult body size and egg size are commonly correlated, as found in the three Brachionus species specified above (Fig. 1). These two arguments, based respectively on the optimum for the adult and on egg development efficiency, work in the same direction. Nevertheless, temperature accelerates metabolic rates and embryonic development in ectotherms, so that a general trend to increased hatching rates with temperature might be also expected. Thus, the question arises whether Bergmann's rule has implications for leaving diapause, or if the general effect of temperature on metabolic rates is the dominant effect.

Previous evidence suggests that rotifers hatch within certain species-specific temperature ranges corresponding to their thermal preference ranges (Pourriot and Snell 1983); the temperatures that support adults are similar to those that promote hatching, though there are exceptions (Cephalodella hoodi: Bell and Weithoff 2003, cited in Schröder 2005). Within-species studies showed that hatchling fitness may increase with diapausing egg size (Brachionus calyciflorus: Kirk 1997; Liu and Niu 2010; Synchaeta pectinata: Kirk 1997), but that diapausing egg size did not influence the hatching pattern at two different temperatures (B. calyciflorus Pallas: Liu and Niu 2010). Moreover, egg size and body size were negatively related to temperature at intraspecific level in B. calyciflorus (Sun and Niu 2012).

Using the opportunity offered by a rotifer cryptic species complex-i.e., their morphological similarity except in size, the aim of this study was to verify whether for the three rotifer species the pattern of hatching from the sediment egg bank is associated with species size in a manner predicted by the extended Bergmann's rule. The response could be manifested in the number of hatchlings at a particular temperature, or the time needed to hatch. We are interested in showing that the developmental acceleration expected at higher temperature does not neutralize completely the expectations from Bergmann's rule. Thus, the tested hypotheses are that, as the body size of the species increases, temperature has (1) an increasingly negative effect on the proportion of hatchlings relative to those of other species, and (2) an increasingly negative effect on the time of hatching. 


\section{Materials and methods}

We used the egg bank from sediments taken from Torreblanca Poza Sur pond $\left(40^{\circ} 08.715^{\prime} \mathrm{N}, 0^{\circ} 10.059^{\prime} \mathrm{E}\right)$ in this study. This pond was the only one in the area where all three Brachionus species were recorded in the egg bank (García-Roger et al. 2008). We used the sediment sample taken from the field in July 2007 and thereafter kept at $4{ }^{\circ} \mathrm{C}$ in the dark until the experiments began in February 2012. Such long storage ensured completion of the obligatory period of diapause; for about one month, diapausing eggs do not respond to hatching induction conditions (Hagiwara and Hino 1989). We exposed the eggs to hatching conditions following the protocol of García-Roger et al. (2008). We transferred sediment aliquots $(15 \pm 0.5 \mathrm{~g}$ wet weight) to twelve $45-\mathrm{ml}$ centrifuge tubes and separated lightweight material, which included diapausing eggs, by sucrose flotation technique (Onbé 1978; Gómez and Carvalho 2000), by which each sample was resuspended in sucrose solution (1:1 sucrose: water) and centrifuged (12.6 $g$ for $5 \mathrm{~min}$ ). We washed the supernatant thoroughly with diluted artificial seawater (Instant Ocean ${ }^{\circledR}$, Aquarium Systems, Sarrebourg Cedex, France) at 6 ppt salinity through 30- $\mu$ m Nytal mesh which retained the diapausing eggs, and kept the eggs in this washing solution to proceed to the hatching bioassay. We selected 6 ppt salinity because previously it was found to be best for induction of diapausing egg hatching in the B. plicatilis species complex from Poza Sur pond (García-Roger et al. 2008). We repeated the procedure of resuspension in sucrose solution, centrifugation and washing the eggs for the remaining organic material of each aliquot. We transferred the material collected from an aliquot to Petri dishes to induce diapausing egg hatching. One sample was accidently poured out, so we divided the 11 remaining Petri dishes among three temperature regimes: $17.5^{\circ} \mathrm{C}$ (four replicates), $22.5{ }^{\circ} \mathrm{C}$ (three replicates) and $25.0^{\circ} \mathrm{C}$ (four replicates). We kept constant illumination in each chamber (c. $75 \mu \mathrm{mol}$ quanta $\mathrm{m}^{-2} \mathrm{~s}^{-1}$ ) to induce hatching. We assigned the location of Petri dishes in the rack randomly and changed it daily. Starting from the next day, we were checking all the Petri dishes daily for hatching and removed the hatchlings. We monitored hatching in the Petri dishes until day 14, when only one hatchling was recorded in all the samples. Then we switched the temperature regimes of the Petri dishes in the low- and high-temperature treatments, and divided two samples from the mid-temperature treatment (the third was accidently poured out on the fourth day of observations) between low and high temperature regimes. We continued checking for hatched individuals daily for another 9 days. We made the final check 3 weeks after switching the regimes. However, this switch worked only as a test of the method we applied and these observations were not analyzed statistically.

To reliably identify the species of the hatchlings found in the Petri dishes, we singly transferred the removed hatchlings to a well in 24-well plates and fed them with culture medium containing the microalga Tetraselmis suecica. After parthenogenetic proliferation, we fixed all clonal cultures founded from the hatchlings with Lugol's solution. First, we identified the cultured species as 'Large' (B. plicatilis) or 'Small' (B. ibericus or rotundiformis) morphotypes according to the description given by Ciros-Pérez et al. (2001a), or as a non-Brachionus species. To differentiate $B$. ibericus from $B$. rotundiformis, we examined each 'Small' morphotype under a microscope (Olympus SZX7, SZX9) and identified it by spine morphology (Ciros-Pérez et al. 2001a). We identified other rotifers as bdelloids, or to species if monogononts, using Koste's (1978) key.

We calculated all statistics in this study with SPSS (IBM SPSS Statistics) 19.0. We analyzed hatching counts in a generalized linear model (GLM) with a factorial design (factors: species and temperature), assuming a Poisson distribution of data and using log as 
link function (Nelder and Wedderburn 1972). In this design the effect of temperature on hatchling counts is affected by the loss of a Petri dish and is not reliable, but the 'species $\times$ temperature' interaction is the relevant effect to test a species-dependent response to temperature $(\mathrm{H} 1)$, and this effect is not affected by the replicate loss. It made no difference for statistical analyses of factor interaction, as the statistical analysis corrects for different counts in each main factor.

Survival analysis can be used to analyze the fate (e.g., death, hatching) of cases (e.g., individuals, eggs) followed through time. We used Cox regression to test for a speciesdependent effect of temperature on hatching time. The dependent variable was the time (in days) from the start of the experiment, and the event was hatching. Both temperature and species were categorical variables. We standardized the first day of hatching by assigning 1 to the day the first hatchling appeared for each replicate independently. For this analysis, we grouped hatching times for each treatment and species combination regardless of the replicate. Cox regression is not affected by the loss of a replicate because it focuses on the average behavior at each temperature.

\section{Results}

A total of 525 hatchlings, most of them belonging to B. rotundiformis (Fig. 2) were obtained and used to found clones and then classified. Another 113 clones were lost before identification. In the replicate lost at $22.5{ }^{\circ} \mathrm{C}$, we observed one B. plicatilis and seven $B$. rotundiformis hatchlings before the day it was lost (day 4 of observations). We included these data in the analysis. More than $80 \%$ hatchings occurred in the first 5 days of incubation. Temperature increased dramatically the propensity to hatch. Hatchlings per sediment gram were 1.28 at $17.5^{\circ} \mathrm{C}, 2.10$ at $22.5{ }^{\circ} \mathrm{C}$ and 5.23 at $25{ }^{\circ} \mathrm{C}$.

The GLM analysis of hatching counts integrated over time shows that both effects (temperature and species) and their interaction are highly significant (Table 1). The species effect may reflect trivial differences in species abundance in the diapausing egg bank, and temperature effect is affected by the amount of tested sediment (i.e., replicate loss). The prediction that a 'species $\times$ temperature' interaction occurs was confirmed by GLM. The smallest species provided higher number of hatchlings regardless incubation temperature, but meaningfully the biggest species decreased its proportion in the total hatchlings with the incubation temperature (Fig. 3). Species percentages responded to temperature with slopes 2.1 for the smallest species (B. rotundiformis), 0.49 for the intermediate species (B. ibericus) and 2.6 for the biggest species (B. plicatilis), so that the slope is higher as the rotifer is smaller.

Cox regression revealed a significant effect of the interaction between species and temperature on the timing of hatching (Table 2; Fig. 2). However, average hatching time at different temperature showed a complex species-dependent pattern (Fig. 4). B. rotundiformis had delayed hatching if compared to the other species, but hatched faster as incubation temperature increased. According to Fig. 2, during the first two days of hatching, B. plicatilis was more abundant than $B$. rotundiformis at $17.5^{\circ} \mathrm{C}$, but the opposite was observed at the higher temperatures.

After switching the cultures to different temperature treatments, we found no Brachionus individuals of the cultures switched from 22.5 or $25.0^{\circ} \mathrm{C}$ at $17.5^{\circ} \mathrm{C}$. At $25.0^{\circ} \mathrm{C}$, we noted one B. ibericus, two B. plicatilis and 24 B. rotundiformis. Three clones were lost before identification. Apart from Brachionus, 11 other rotifers hatched in the course of the experiment: four bdelloids (at all three temperatures), one Lecane hastata $\left(25.0^{\circ} \mathrm{C}\right)$ and 

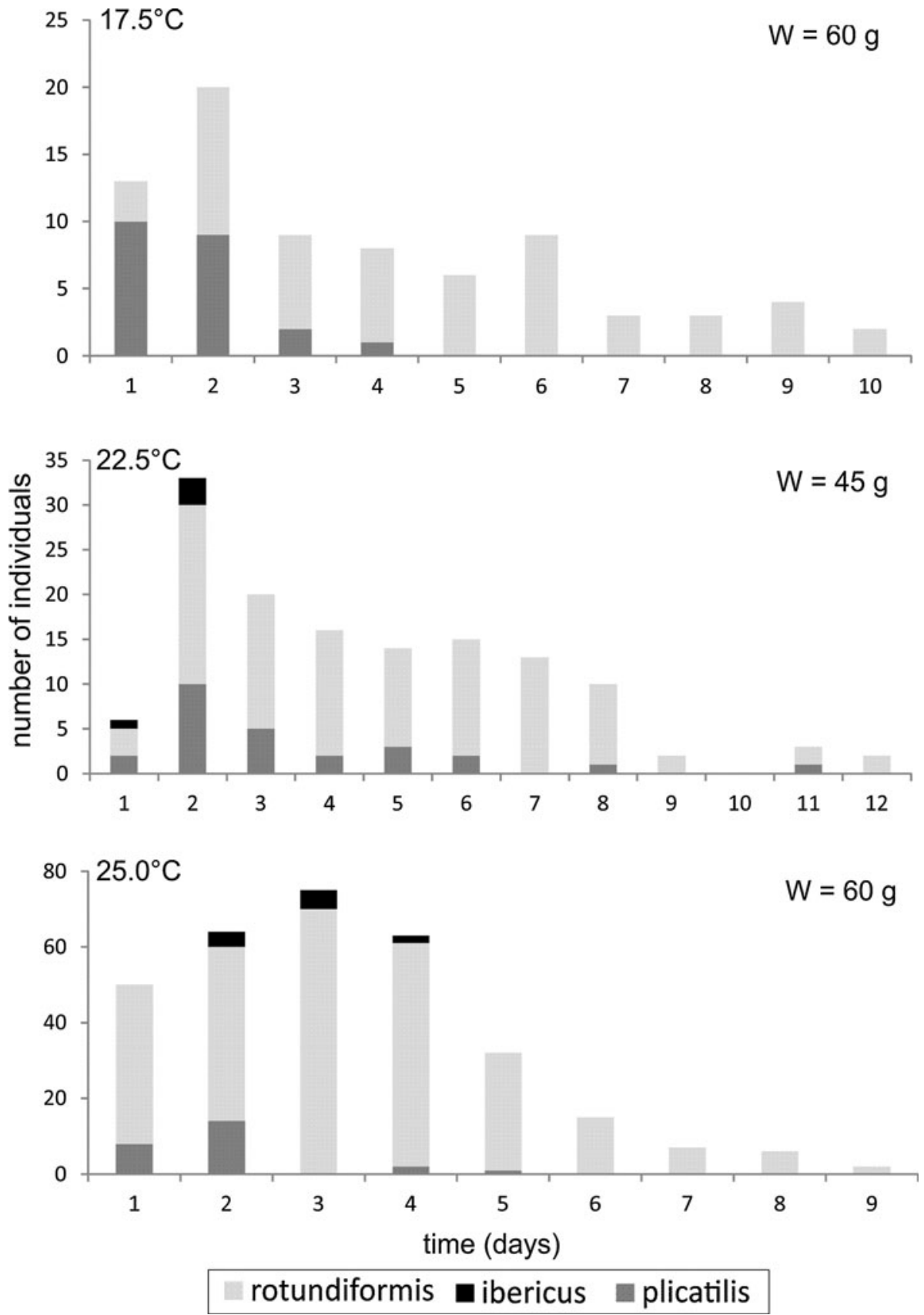

Fig. 2 Number of individuals of the three Brachionus species hatched from the sediment egg bank on consecutive days of the experiment under three temperature regimes. The first day was standardized to the day the first hatchling appeared, for each replicate independently. The numbers of individuals were then summed for all replicates of a temperature treatment. W-total wet weight of sediment used to extract resting eggs 
Table 1 GLM analysis of effect of temperature on hatching species

\begin{tabular}{llll}
\hline Factor & $\begin{array}{l}\text { Wald } \\
\text { Chi-square }\end{array}$ & $d f$ & $P$ \\
\hline Intercept & 281.4 & 1 & $<0.001$ \\
Temperature & 24.2 & 2 & $<0.001$ \\
Species & 69.5 & 2 & $<0.001$ \\
Temperature $\times$ species & 24.8 & 3 & $<0.001$ \\
\hline
\end{tabular}

Fig. 3 Species percentage in the hatchings observed at the experimental temperatures for diapausing egg incubation. Lines were fitted using the least square method. Vertical bars indicate standard error estimations based on a binomial distribution

Table 2 Cox regression analysis of effect of temperature on timing of species hatching

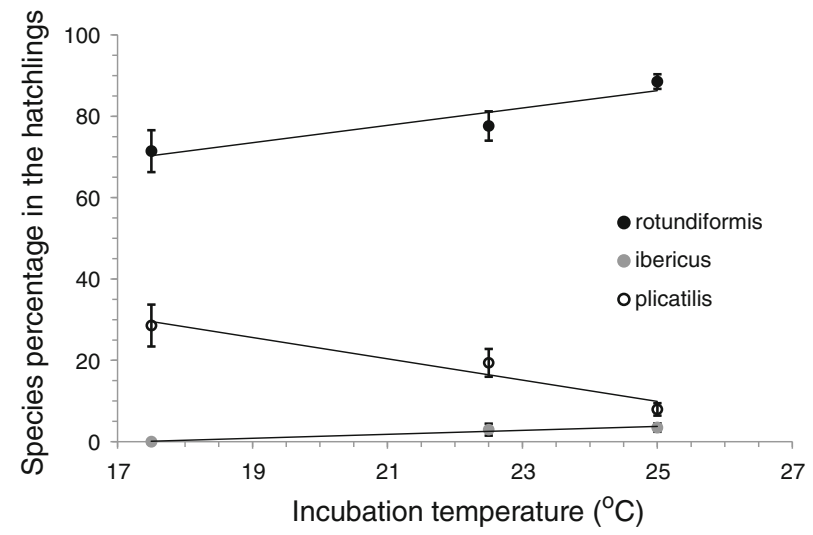

\begin{tabular}{lllr}
\hline Factor & Wald & $d f$ & $P$ \\
& Chi-square & & \\
\hline Temperature & 29.9 & 2 & $<0.001$ \\
Species & 17.7 & 2 & $<0.001$ \\
Temperature $\times$ species & 17.1 & 3 & 0.001 \\
\hline
\end{tabular}

Fig. 4 Average incubation time for hatching

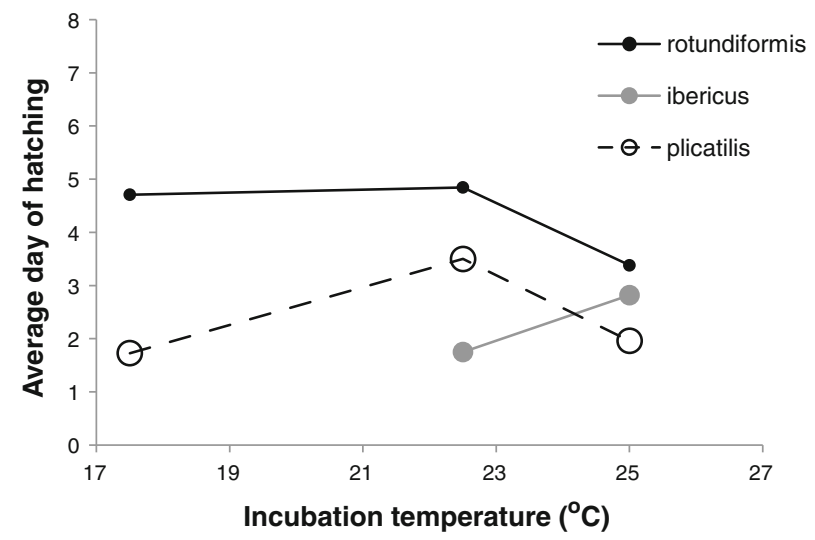

five Lecane inermis (one at $25.0^{\circ} \mathrm{C}$ before the switch, one at $17.5^{\circ} \mathrm{C}$ after the switch, and three at $25.0^{\circ} \mathrm{C}$ after the switch). One individual, probably Lecane, died before founding a clone. 


\section{Discussion}

Our results show clearly that the response to temperature of hatching from the sediment egg bank is species-dependent. This is an important finding, reported here for cryptic rotifer species for the first time. Moreover, the results given in Fig. 3, when combined with species body size, show an association between the diapause egg hatching response to temperature and organism size. The biggest species increased its proportion in the hatchlings as temperature decreased. The intermediate size species $B$. ibericus showed an intermediate pattern, although based on a low number of hatchlings. Besides this species differences, an underlying general effect of temperature on the number of hatchings seems likely, as temperature increased dramatically this number. This general tendency could be partially due the dominance of the smallest species in the hatchlings. However, the three species tended to respond positively to temperature, but with different intensity. In summary, our results suggest that temperature favors hatching, presumably by accelerating embryonic development, but that the species size is correlated to the proportions of hatching in a way consistent with Bergmann's rule.

Comparing only three species is somewhat limited. Nevertheless, the number of systems where three cryptic, sympatric species can be compared is also limited. We suggest that our experimental system, which compares species with very similar ecology, is particularly appropriate to isolate a body size effect. The response of the intermediate size species showed in Fig. 3 reinforces our conclusion of the implication of Bergmann' rule in this system.

Contrarily to the hatching proportions, the timing of hatching showed a more complex pattern, and the average incubation time to hatching did not confirm completely Bergmann's rule. The exception is that $B$. plicatilis had shorter average time to hatching at 25 than at $22.5{ }^{\circ} \mathrm{C}$ (Fig. 4), while the expectation was an increase steeper than in $B$. ibericus, the intermediate size species. Since the early-hatched eggs start early clonal proliferation, they are expected to contribute more to the populations than the late hatched eggs. Given the high growth rates these rotifers have during the parthenogenetic proliferation phase, starting early may provide a high advantage. Therefore, it is relevant to know what happens in the first days of hatching. If the analysis is restricted to the biggest and the smallest species, since $B$. ibericus contribute with few hatchlings, we see that the expectation for Bergmann's rules holds because B. plicatilis, the largest, was three times more abundant than $B$. rotundiformis at $17.5^{\circ} \mathrm{C}$, but at the higher temperatures $B$. rotundiformis, the smallest, was twice $(22.5)$ and five times $\left(25.0{ }^{\circ} \mathrm{C}\right)$ more abundant than B. plicatilis.

Potentially, hatchability might be affected by many factors, for example by salinity (Kim and Hagiwara 2011a) or by age of mother (Kim and Hagiwara 2011b). However, our results show temperature acts differentially on the egg bank of each species, so that temperature effect is not masked by other factors. Moreover, we intentionally did not control for factors during egg formation because we wanted to know the response in eggs collected in the wild, from natural populations. The temperature-associated proportions of hatching in the three Brachionus species are mostly in accordance with the thermal preferences of adults (Gómez et al. 1995): of the three, B. plicatilis, the "winter" species, is best adapted to low temperature and lives at $10.0{ }^{\circ} \mathrm{C}$; the bigger of the "summer" species, B. ibericus, can live at $15.0{ }^{\circ} \mathrm{C}$; the smallest "summer" species, B. rotundiformis, prefers higher temperatures (Gómez et al. 1997).

The low number of B. ibericus that hatched in the course of the experiment is in agreement with previous research. In a study of hatching from Poza Sur sediments, García-Roger 
(2006a) found that B. plicatilis, B. rotundiformis and B. ibericus contributed 44.7, 42.6 and $12.7 \%$ respectively. The shares of $B$. plicatilis to $B$. ibericus were similar to those in the present study, while the share of $B$. rotundiformis hatchlings was lower. That difference may be due to the lower temperature they used, $20^{\circ} \mathrm{C}$, which in light of our study appears suboptimal.

The unidentified clones should not affect the general pattern found, because the share of each species among them was most probably random. Moreover, the number of clones that were not identified because they did not proliferate increased with the day of observation, meaning that individuals hatching after some critical time were not viable. García-Roger (2006b), however, found that $99.4 \%$ of hatchlings survived to maturity. The discrepancy between survival rates might be due to long storage of the sediment under laboratory conditions in our study.

This study demonstrated that size is adaptive for temperature in the B. plicatilis cryptic species complex. The study focused on egg size, a good proxy for adult size at interspecific level (Pourriot and Snell 1983; our Fig. 1); it is justified to infer that what is actually adaptive for temperature is the adult size of a species. Nevertheless, temperature is associated in nature with other ecologically relevant factors, and low-temperature species are expected to be adapted at a suit of factors. For instance, B. plicatilis seems to be adapted to environmental fluctuations (Carmona et al. 1995) and it is likely more eurioic than the other species studied here. Besides Bergmann's rule at work, this could explain partially our results, as $B$. plicatilis seems to be less temperature-specialized. The short times needed for their diapausing eggs to hatch, despite the large size of these eggs, are also consistent with an opportunistic strategy, expectable to evolve in a fluctuating scenario.

In summary, by studying a set of sympatric, cryptic species, we showed the applicability of Bergmann's rule to life-history traits associated to diapause, although our results suggest that additional selective factors might have modeled those traits.

Acknowledgments We are grateful to Maria Jose Carmona, Carmen Gabaldón, Eduardo García-Roger and Javier Montero-Pau for advice and assistance at all stages of the study and two anonymous referees for valuable comments on previous versions of the manuscript. We thank Eduardo García-Roger for identifying nonBrachionus species and M. Jacobs for editing the text. The study was funded by the Foundation for Polish Science (POMOST/2011-3/12) and the Spanish Ministry of Economy and Competitiveness (CGL2009-07364).

Open Access This article is distributed under the terms of the Creative Commons Attribution License which permits any use, distribution, and reproduction in any medium, provided the original author(s) and the source are credited.

\section{References}

Angilletta MJ Jr (2008) Thermal adaptation: a theoretical and empirical synthesis. Oxford University Press, Oxford

Angilletta MJ Jr, Dunham AE (2003) The temperature-size rule in ectotherms: simple evolutionary explanations may not be general. Am Nat 162:332-342

Bell EM, Weithoff G (2003) Benthic recruitment of zooplankton in an acidic lake. J Exp Mar Biol Ecol 285(286):205-219

Bergmann C (1847) Über die verhältnisse der warmeökonomie der thiere zuihrer grosse. Gött Stud 1:595-708

Carmona MJ, Gómez A, Serra M (1995) Mictic pattern of the Brachionus plicatilis Müller 1786 in small ponds. Hydrobiologia 313(314):365-371

Ciros-Pérez J, Gómez A, Serra M (2001a) On the taxonomy of three sympatric sibling species of the Brachionus plicatilis (Rotifera) complex from Spain, with the description of B. ibericus $\mathrm{n}$. sp. J Plankton Res 23:1311-1328 
Ciros-Pérez J, Carmona MJ, Serra M (2001b) Resource competition between sympatric sibling rotifer species. Limnol Oceanogr 46:1511-1523

García-Roger EM (2006a) Análisis demográfico de bancos de huevos diapáusicos de rotíferos. PhD dissertation, Institute Cavanilles, University of Valencia, Valencia, Spain

García-Roger EM (2006b) Hatching and viability of rotifer diapausing eggs collected from pond sediments. Fresh Biol 51:1351-1358

García-Roger EM, Armengol-Díaz X, Carmona MJ, Serra M (2008) Assessing rotifer diapausing egg bank diversity and abundance in brackish temporary environments: an ex situ sediment incubation approach. Fund Appl Limnol 173:79-88

Gómez A, Carvalho GR (2000) Sex, parthenogenesis and the genetic structure of rotifers: microsatellite analysis of contemporary and resting egg bank populations. Mol Ecol 9:203-214

Gómez A, Temprano M, Serra M (1995) Ecological genetics of a cyclical parthenogen in temporary habitats. J Evol Biol 8:601-622

Gómez A, Carmona MJ, Serra M (1997) Ecological factors affecting gene flow in the Brachionus plicatilis complex (Rotifera). Oecologia 111:350-356

Hagiwara A, Hino A (1989) Effect of incubation and preservation on resting egg hatching and mixis in the derived clones of the rotifer Brachionus plicatilis. Hydrobiologia 186/187:415-421

Kim HJ, Hagiwara A (2011a) Effect of salinity during resting egg formation and hatching on descendent reproduction in the rotifer Brachionus rotundiformis Tschugunoff. J Plankton Res 33:1033-1042

Kim HJ, Hagiwara A (2011b) Effect of female aging on the morphology and hatchability of resting eggs in the rotifer Brachionus plicatilis Müller. Hydrobiologia 662:107-111

Kirk KL (1997) Egg size, offspring quality and food level in planktonic rotifers. Fresh Biol 37:515-521

Koste W (1978) Rotatoria. Die Rädertiere Mitteleuropas. (Oberordnung Monogononta.). Gebrüder Borntraeger, Stuttgart

Lapesa S, Snell TW, Fields DM, Serra M (2002) Predatory interactions between a cyclopoid copepod and three sibling rotifer species. Fresh Biol 47:1685-1695

Lapesa S, Snell TW, Fields DM, Serra M (2004) Selective feeding on Arctodiaptomus salinus (Copepoda, Calanoida) on co-occurring sibling rotifer species. Fresh Biol 49:1053-1061

Liu W, Niu CJ (2010) Polymorphism in resting egg size and hatching strategy in the rotifer Brachionus calyciflorus Pallas. Zool Sci 27:330-337

Montero-Pau J, Serra M (2011) Life-cycle switching and coexistence of species with no niche differentiation. PLoS ONE 6:e20314

Montero-Pau J, Ramos-Rodriguez E, Serra M, Gómez A (2011) Long-term coexistence of rotifer cryptic species. PLoS ONE 6:e21530

Nelder JA, Wedderburn RWM (1972) Generalized linear models. J R Stat Soc A 135:370-384

Onbé T (1978) Sugar flotation method for sorting the resting eggs of marine cladocerans and copepods from sea-bottom sediment. Bull Jpn Soc Sci Fish 44:1411

Ortells R, Gómez A, Serra M (2003) Coexistence of cryptic rotifer species: ecological and genetic characterisation of Brachionus plicatilis. Fresh Biol 48:2194-2202

Pourriot R, Snell TW (1983) Resting eggs in rotifers. Hydrobiologia 104:213-224

Schröder T (2005) Diapause in monogonont rotifers. Hydrobiologia 546:291-306

Serra M, King CE (2001) Optimal rates of bisexual reproduction in cyclical parthenogens with densitydependent growth. J Evol Biol 12:263-271

Suatoni EM (2003) Patterns of speciation in the Rotifer species complex, Brachionus plicatilis. PhD dissertation. Yale University, New Haven, CT

Sun D, Niu C (2012) Adaptive significance of temperature induced egg size plasticity in a planktonic rotifer, Brachionus calyciflorus. J Plankton Res 34:864-873

Walker KF (1981) A synopsis of ecological information on the saline lake rotifer Brachionus plicatilis Müller 1786. Hydrobiologia 81:159-167

Watt C, Mitchell S, Salewski V (2010) Bergmann's rule: a concept cluster? Oikos 119:89-100 